\title{
FIBRE REMOTE OPTOELECTRONIC GAMMA DOSIMETRY BASED ON OPTICALLY STIMULATED LUMINESCENCE $\mathrm{OF} \mathrm{Al}_{2} \mathrm{O}_{3}: \mathrm{C}$
}

\author{
G. Ranchoux, S. Magne, J. P. Bouvet and P. Ferdinand \\ CEA-LIST (DIMRI-SiAR-LMO), CEA/Saclay \\ 91191 Gif-sur-Yvette, France
}

\begin{abstract}
Optically stimulated luminescence dosimetry (OSL-D) used in conjunction with fibre optics enables a remote measurement of dose, for the purpose of radioprotection in the nuclear industry and in medicine (radiology, radiotherapy). Alumina OSL crystals are used because of their low Z, low fading and optical transparency, which improves the sensitivity. An optoelectronic portable dosemeter has been designed and tested that shows a dose detection of $50 \mu$ Gy with a 20 metre-long fibre. Following irradiation, all trapped electrons are released under light stimulation while the OSL is integrated to provide doseequivalent measurements. A compensation technique is designed with the help of the MCNP4b code, so that both angular and photon energy characteristics comply with international standards (CEI 61066) for photon dose equivalent $\mathrm{H}_{\mathrm{p}}(10)$. Two sensors are described that allow measurements over a wide solid angle $(95 \%$ of $4 \pi \mathrm{Sr})$, for photon energies ranging from $15 \mathrm{keV}$ to $3 \mathrm{MeV}$.
\end{abstract}

\section{INTRODUCTION AND BACKGROUND}

In the nuclear industry, radiation protection is an important matter of concern. At present, dosimetry is achieved with photographic films (legal dosemeters), thermoluminescent dosemeters (TLD) and electronic ones. All of them measure individual dose at critical locations. In the frame of the ALARA concept (as low as reasonably achievable), optically stimulated luminescence (OSL) has been investigated in our laboratory since 1993 for the purpose of improving remote dosimetry monitoring. The OSL phenomenon is closely related to thermoluminescence. So, as for TLDs, free electrons induced by ionising radiation (UV, $\mathrm{X}, \gamma, \ldots$ ) are trapped on stable energy levels in OSL materials. But, instead of being released thermally, electrons are released on request, by stimulation light, and produce a luminescence which is proportional to the 'data stored' left by irradiation, enabling the dose measurement. The OSL phenomenon offers the same advantages as TLD plus the interesting possibility of a remote optical stimulation. On this assumption, a first radiation sensor based on rare-earth doped alkaline earth sulphides (AES) such as $\mathrm{BaS}, \mathrm{MgS}$ or $\mathrm{CaS}^{(1)}$ which can be stimulated with an infrared light, coupled with an optical fibre several kilometres long has been achieved. This instrument allows remote dose measurements from about $1 \mathrm{mGy}$ up to several $\mathrm{Gy}^{(2)}$. However, such a device cannot be used for personal dosimetry for several reasons. First of all, AES are characterised by higher effective atomic numbers $(Z>14)$ than that of tissues $(\approx 7)$ making compensation very difficult to achieve. Moreover, these materials exhibit an important signal fading at room temperature. Finally, the required dose equivalent threshold for personal dosimetry (about $10 \mu \mathrm{Gy}$ ) could not

Contact Author E-mail: Sylvain.Magne@cea.fr be reached because of a limited interaction volume. This is due to the fact that AES materials are opaque to infrared and visible light, and only a small part of the information can be extracted from the superficial area of the material and collected by the optical fibre. In this way, transparent OSL materials such as alumina crystals ${ }^{(3,4)}$, $\mathrm{Cu}^{+}$-doped $\mathrm{SiO}_{2}$ fibres ${ }^{(5,6)}, \mathrm{Eu}^{2+}$-doped $\mathrm{BaFBr}^{(7,8)}$ or In-doped $\mathrm{KBr}^{(9,10)}$ have been studied. Only alumina pellets and crystals and silica fibres can be retained as they are characterised by an effective atomic number relatively close to tissues. In a second part, the integration of the fibre remote optoelectronic dosemeter based on OSL alumina detectors and developed by the CEA-LIST is described and its features (linearity, reproducibility and dose equivalent threshold) are discussed. In a third part, the energy and the incident angle compensation of the sensor heads is achieved with the Monte Carlo code MCNP4 $b^{(11)}$, in order to comply with international standards (CEI 61066). In this way, the spectral and angular responses of several compensation geometries (filters thickness and nature) are compared.

\section{TEST OF PHOTOSTIMULATED TRANSPARENT AND LOW-Z MATERIALS FOR OSL PERSONAL DOSIMETRY}

In order to improve both the dose threshold and sensitivity of the fibre remote OSL dosemeter to gamma radiation (to replace alkaline earth sulphide), $\alpha$-alumina pellets and $\mathrm{Cu}^{+}$-doped silica fibres have been tested at the Optical Measurement Laboratory of the CEA-LIST, based in Saclay, France.

Alumina $\left(\alpha-\mathrm{Al}_{2} \mathrm{O}_{3}: \mathrm{C}\right)^{(3)}$ is a chemically stable and transparent crystal grown in a highly reducing atmosphere in the presence of carbon, under carefully controlled conditions, in such a way that high concentrations of $\mathrm{F}$ and $\mathrm{F}^{+}$centres are created ${ }^{(12)}$. These 
alumina samples are single crystals, of $5 \mathrm{~mm}$ diameter and approximately $1 \mathrm{~mm}$ thick.

The $\mathrm{Cu}^{+}$-doped silica is a photochromic glass. Following radiation exposure, the copper ion valence state changes $\left(\mathrm{Cu}^{+} \rightarrow \mathrm{Cu}^{2+}\right)$ and a broad absorption band centred around $800 \mathrm{~nm}$ appears ${ }^{(5)}$. The very weak copper doping level (only about $10 \mathrm{ppm}$ ) is obtained by thermal diffusion at $1100^{\circ} \mathrm{C}$.

Table 1 sums up the optical properties of alumina crystals, silica fibres and alkaline earth sulphide $(\mathrm{MgS})$ powders. All these materials have been tested with the same laser bench described in Figure 1. A titaniumsapphire laser with a RG780 filter (to remove visible fluorescence) was used for stimulating the silica fibre $(860 \mathrm{~nm})$ and the $\mathrm{MgS}(980 \mathrm{~nm}) . \mathrm{Al}_{2} \mathrm{O}_{3}$ was stimulated by $514.5 \mathrm{~nm}$ laser light $\left(\mathrm{Ar}^{+}\right)$filtered with a diffraction grating and a band-pass filter to remove blue fluorescence. These materials were irradiated with a ${ }^{137} \mathrm{Cs}$ source emitting $662 \mathrm{keV}$ photons. A 1.5 metre-long

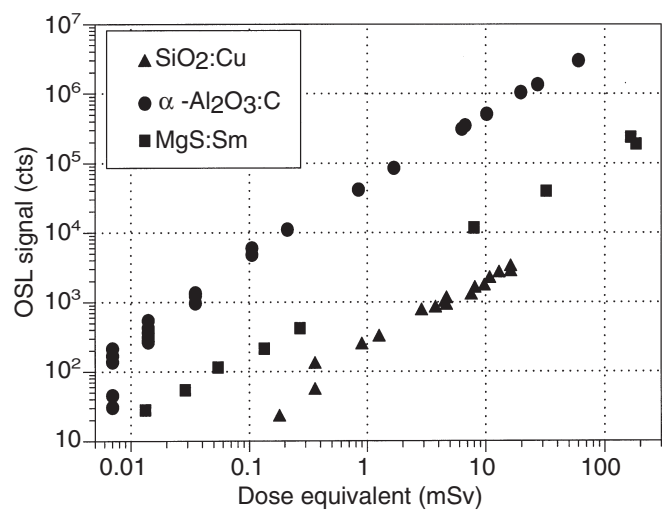

Figure 2. Response of three OSL materials for fibre remote dosimetry tested with the experimental OSL bench.

Table 1. Properties of the OSL materials tested: $\mathrm{MgS}: \mathrm{Sm}, \mathrm{SiO}_{2}: \mathrm{Cu}^{+}$and $\mathrm{Al}_{2} \mathrm{O}_{3}: \mathrm{C}$

\begin{tabular}{|c|c|c|c|c|c|c|}
\hline Material & $\begin{array}{l}\text { Peak emission } \\
\text { wavelength } \\
(\mathrm{nm})\end{array}$ & $\begin{array}{l}\text { Peak stimulation } \\
\text { wavelength } \\
(\mathrm{nm})\end{array}$ & $\begin{array}{c}\text { Detection } \\
\text { threshold } \\
(\mu \mathrm{Gy})\end{array}$ & $\begin{array}{l}\text { Sensitivity } \\
\text { (cts/ } / \mu \mathrm{Gy} \text { ) }\end{array}$ & $\begin{array}{l}\mathrm{T}_{\mathrm{TL}}(\mathrm{K}) \\
\text { (glow } \\
\text { curve) }\end{array}$ & $\begin{array}{c}\text { Effective } \\
\quad \mathrm{Z}\end{array}$ \\
\hline $\mathrm{MgS}: \mathrm{Sm}$ & $\begin{array}{l}600 \\
(560 \text { to } 650)\end{array}$ & $\begin{array}{l}1000 \\
\text { (850 to } 1200)\end{array}$ & 10 & 2 & $\begin{array}{l}300 \text { to } \\
550\end{array}$ & 14 \\
\hline $\mathrm{SiO}_{2}: \mathrm{Cu}^{+}$ & $\begin{array}{l}540 \\
\text { (450 to } 600 \text { ) }\end{array}$ & $\begin{array}{l}800 \\
\text { (700 to } 900)\end{array}$ & 100 & 0.2 & $\begin{array}{l}300 \text { to } \\
650\end{array}$ & 10 \\
\hline $\mathrm{Al}_{2} \mathrm{O}_{3}: \mathrm{C}$ & $\begin{array}{l}410 \\
(350 \text { to } 450)\end{array}$ & 450 to 530 & 10 & 50 & $\begin{array}{l}400 \text { to } \\
470\end{array}$ & 10 \\
\hline
\end{tabular}

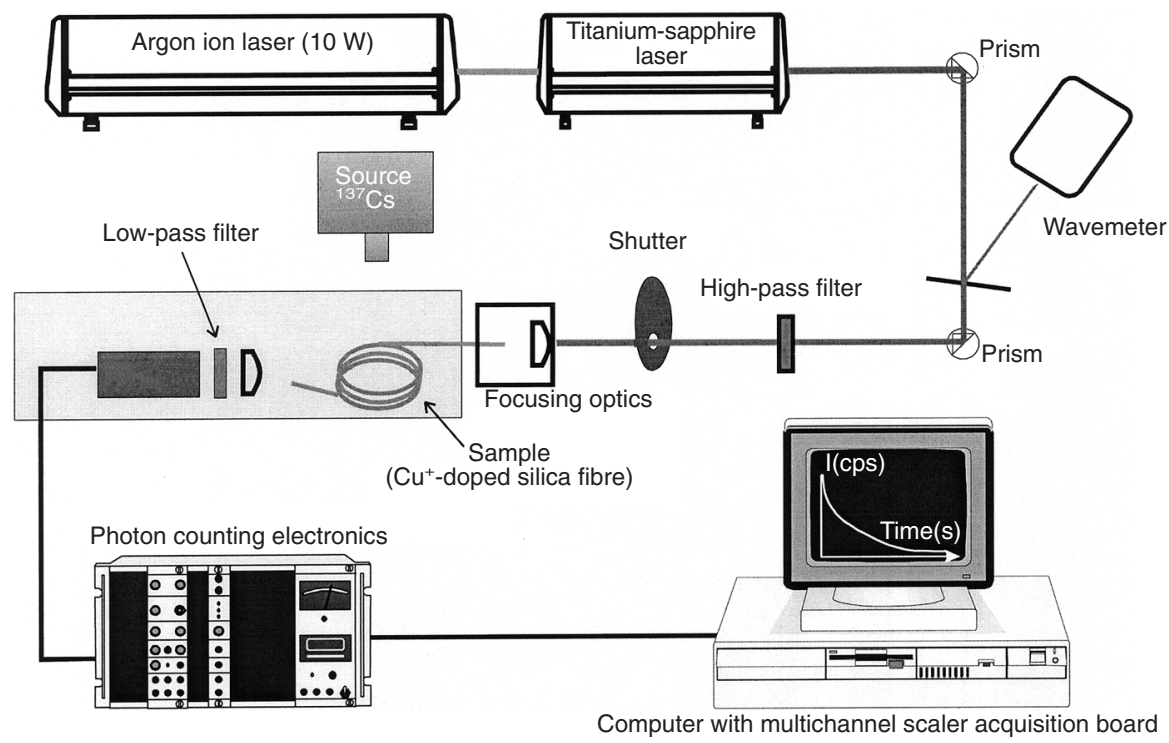

Figure 1. Experimental OSL test bench. 


\section{REMOTE DOSIMETRY USING OSL OF $\mathrm{Al}_{2} \mathrm{O}_{3}: \mathrm{C}$}

silica fibre (diameter $\approx 600 \mu \mathrm{m}$ ) was coiled around a mandrel. A photomultiplier (R928) was used in photon counting mode and the pre-amplified pulses were converted into TTL format and monitored with a nucleus board operating in the multi-channel scaler mode. An electromagnetic shutter triggered monitoring and the OSL was observed under a continuous-wave laser stimulation. Different coloured filters were used to avoid the simultaneous detection of the stimulation light by the photomultiplier and thus decrease background noise. A $15 \mathrm{~dB}$ decrease in OSL signal is observed after a stimulation period of about one minute for all materials (50 mW laser stimulation). Figure 2 presents the integrals of OSL pulses relative to dose for both transparent materials described above, and compares their OSL sensitivity with that of $\mathrm{MgS}$.

For a given collection angle, the silica fibre sensitivity is limited by the copper concentration (several ppm) and the $\mathrm{MgS}$ one is limited by the stimulated area of the sample. Therefore, alumina, because of its OSL performances (efficiency, transparency, low effective Z, low fading at room temperature, availability on the market) is a very good candidate for use in a fibre optic remote dosemeter.

\section{FIBRE REMOTE OPTOELECTRONIC DOSEMETER USING ALUMINA CRYSTALS}

A portable demonstrator of a fibre remote optoelectronic dosemeter using alumina crystals has been developed, in order to be used on nuclear sites (Figure 3 ). This device is made up of three parts: (1) the sensor head containing both the alumina pellets and the focusing optics, both packaged in an aluminum shell, (2) the central unit including a compact CW doubled-YAG laser emitting a $532 \mathrm{~nm}$ green light triggered by an electromagnetic shutter and a photomultiplier tube operating in photon counting mode, and (3) the silica fibre which allows the light to be guided from the sensor head to the central unit. The aluminium-covered sensor head has the same shape as the sensor designed in Figure 6 (but with an Al package instead of a polycarbonate package and no tin filters).

The OSL signal is monitored as a function of time on a portable PC and is integrated over a period of 20 min corresponding to a $-20 \mathrm{~dB}$ dump time of the trap levels (laser power is $30 \mathrm{~mW} ; 8 \mathrm{~mW}$ in the sensor head).

The device principle can be divided into two separated steps: (1) Irradiation: during an exposure of the sensor head to ionising radiations, the trap energy levels of the OSL material are filled by secondary electrons and the dose information is stored; (2) Reading: first of all, the green stimulation light emitted by the laser is transmitted by the optical fibre to the sensor, and provides enough energy to release the trapped electrons. During electron recombining, a blue OSL light (420 nm) is emitted by the alumina crystal with an intensity proportional to the absorbed dose and, then, is collected and transmitted by the same optical fibre to the photomultiplier tube. The central unit also incorporates a set of optical filters able to remove background lights such as infrared light from the laser $(1064 \mathrm{~nm})$ or red light $(695 \mathrm{~nm})$ from the $\mathrm{Cr}^{3+}$ impurities of the alumina crystal lattice, and a dichroic beamsplitter allowing the OSL signal to be set towards the photomultiplier tube.

For testing purpose, the sensor head is irradiated with a ${ }^{137} \mathrm{Cs}$ source corresponding to a $55 \mu \mathrm{Sv} \cdot \mathrm{min}^{-1}$ dose equivalent rate at $10 \mathrm{~mm}$ depth in the human body. The OSL signal decay is recorded for several equivalent doses and integrated over $20 \mathrm{~min}$. The $\mathrm{H}_{\mathrm{P}}(10)$ calibration curve of this fibre remote OSL dosemeter, presented in Figure 4, is linear from about $100 \mu \mathrm{Sv}$ up to more than $1 \mathrm{~Sv}$. The measurement error increases as the dose decreases (the error is about $10 \%$ for a dose of $100 \mu \mathrm{Sv})$.

However, the international standard IEC 61066 recommends that the measured value does not differ from the conventional true value $\mathrm{H}_{\mathrm{P}}(10)^{(13)}$ by more than $30 \%$

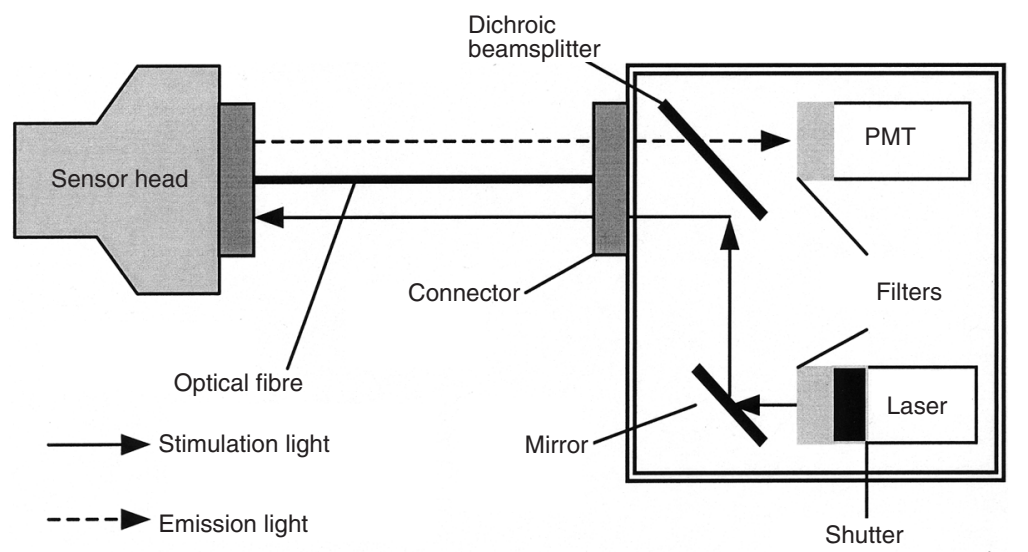

Figure 3. Simplified schema of the fibre remote optoelectronic dosemeter. 


\section{G. RANCHOUX, S. MAGNE, J. P. BOUVET and P. FERDINAND}

when the sensor head is irradiated with photons of energy ranging from $15 \mathrm{keV}$ to $3 \mathrm{MeV}$. Moreover, the response at incidence angles of $20^{\circ}, 40^{\circ}$ and $60^{\circ}$ from normal incidence must not differ from the normal incidence response by more than $15 \%$ when irradiated with $60 \mathrm{keV}$ photons. As shown in Figures 7 and 8 below, the dosimetric response defined as the ratio between the measured value and the conventional true value $\mathrm{H}_{\mathrm{P}}(10)$ of the current detector with aluminium coating does not comply with international standard recommendations, neither with respect to photon energy, nor to incident photon angle. Therefore, a new sensor head needs to be designed for personal dosimetry purposes.

\section{DESIGN OF A PHOTON ENERGY AND ANGULAR COMPENSATED OPTICAL SENSOR}

Two different sensor heads have been designed and are presented in this section. In both cases, the described compensation process uses tin tube-shaped screens without any perforation with a cover proportion chosen in such a way as to comply with IEC 61066 standard (about 60 to $70 \%$ ). Screens can also be manufactured with lead or indium but the absorption peak (K-line), in the energy photon ranging from $15 \mathrm{keV}$ to $3 \mathrm{MeV}$, renders the compensation more difficult to achieve.

Figure 5 describes a sensor head with a butt-coupled alumina crystal. This includes a $5 \mathrm{~mm}$ long and $1.5 \mathrm{~mm}$ diameter alumina crystal cylinder and a silica optical fibre $($ N.A. $=0.5$, core diameter $=1 \mathrm{~mm}$ ). The OSL light generated during the laser stimulation is collected by the optical fibre after several reflections on a $50 \mu \mathrm{m}$ thick aluminium film wound around the crystal. This film also reduces the number of secondary electrons or recoil particles, which may interact into the crystal during a mixed photon, electron and neutron irradiation. This sensor head contains a polycarbonate cylindrical

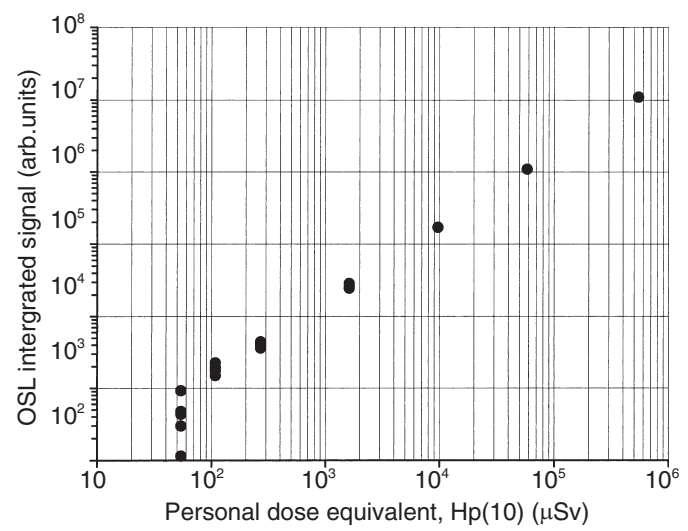

Figure 4. OSL integrated signal plotted against dose equivalent $\mathrm{H}_{\mathrm{p}}(10)$ measured with the fibre remote OSL dosemeter. brace guiding the crystal and keeping the $500 \mu \mathrm{m}$ thick tin screen in position for energy compensation in perpendicular irradiations. This cylindrical tin screen covers approximately $70 \%$ of the crystal surface. In a similar way, another $200 \mu \mathrm{m}$ thick and $1.5 \mathrm{~mm}$ diameter disc shaped screen is inserted between the plastic shell and the crystal, in order to compensate for angular photon dependence close to the cylinder axis.

Figure 6 shows an optically coupled sensor head. In such a configuration, the sensor head contains a 5-cylindrical-alumina-pellet stack (total length $=5 \mathrm{~mm}$, diameter $=5 \mathrm{~mm}$ ). With such a device, the OSL light is sent back to the optical fibre thanks to a mirror and a converging lens. In order to achieve both energy and angular compensations, this device contains a polycarbonate cylindrical brace supporting a $700 \mu \mathrm{m}$ thick cylindrical screen recovering $60 \%$ of the crystal. Moreover, a $5 \mathrm{~mm}$ diameter and $200 \mu \mathrm{m}$ thick disc shaped screen is inserted between the plastic shell and the mirror.

In both configurations, spectral and angular dosimetric responses of the sensor head were modelled with the Monte Carlo code MCNP4b and compared with the conventional true value $\operatorname{Hp}(10)^{(13)}$, as shown in Figures

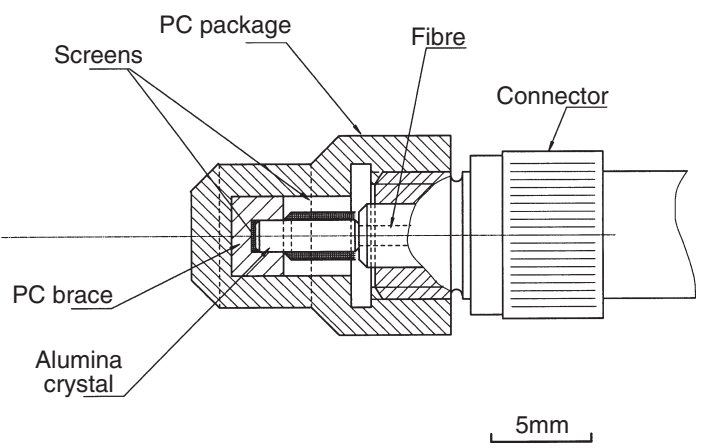

Figure 5. Butt-coupled sensor head.

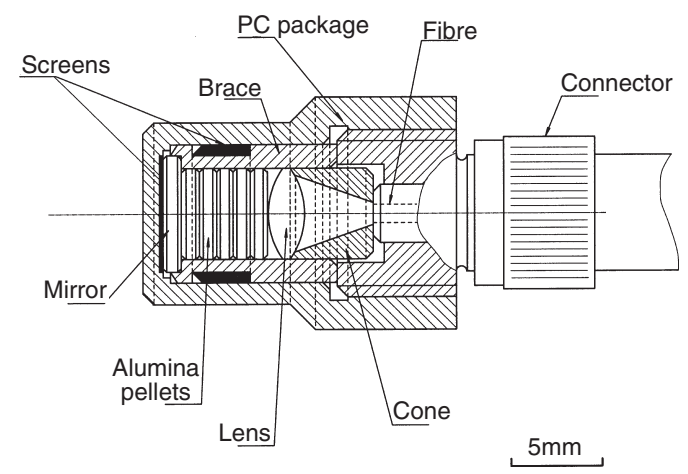

Figure 6. Optically coupled sensor head. 
7 and 8. The design of the butt-coupled sensor head allows the energy compensation from $15 \mathrm{keV}$ to $3 \mathrm{MeV}$ since the deviation with respect to the ${ }^{137} \mathrm{Cs}$ calibrated response is lower than $30 \%$. For $60 \mathrm{keV}$ photons, the international standard is respected (stable response \pm $15 \%$ ) for a photon incident angle from $90^{\circ}$ (i.e. fibre axis) up to $-60^{\circ}$ corresponding to a wide operational angle of $\pm 150^{\circ}$. Obviously, a totally isotropic angular response is not achievable because of the fibre connector. Finally, an energy compensation can be achieved for the optically coupled sensor from $20 \mathrm{keV}$ up to more than $3 \mathrm{MeV}$. The allowed operational angle is $\pm 155^{\circ}$, corresponding to photon incident angles ranging from $90^{\circ}$ up to $-65^{\circ}$. All these promising calculated results will have to be proved experimentally.

\section{CONCLUSION AND FURTHER DEVELOPMENTS}

The feasibility has been demonstrated of a remote, quasi real-time OSL radioprotection instrument using alumina crystals that allows a dose equivalent threshold of about $50 \mu \mathrm{Sv}$. The sensor heads, designed with the

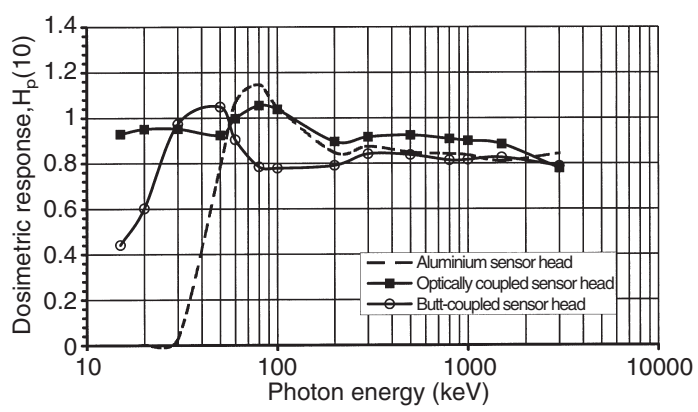

Figure 7. Calculated $\mathrm{H}_{\mathrm{p}}(10)$ response plotted against radiation energy for several fibre remote detectors for radiation incidence perpendicular to fibre axis. help of the MCNP4b code, comply with the IEC 61066 standard for radioprotection for energy compensation (photon energy ranging from $15 \mathrm{keV}$ to $3 \mathrm{MeV}$ ) and exceeds its recommendation for angular compensation (wide operational angle of $\pm 150^{\circ}$ corresponding to $95 \%$ of space $(4 \pi \mathrm{Sr})$ ). Experimental validations remain to be done to fully qualify this sensor for radioprotection.

Since the OSL decay time is, at first glance, inversely proportional to laser power, an increase in laser power will decrease the reading period (a laser power of 200 $\mathrm{mW}$ would set the reset time to $3 \mathrm{~min}$ ). This would also help to improve the dose equivalent threshold. In the same way, the use of quartz fibres may help improve optical transmission and therefore help increase the fibre length.

Concerning radiation detection, these aluminiumcovered sensors can be applied to the monitoring of nuclear installations and particularly in areas out of reach for usual dosemeters. For example, a first generation sensor ${ }^{(2)}$ is routinely inserted in small diameter pipes (typically $10 \mathrm{~mm}$ ) both for real-time dose measurements and for remote accident detection (radioactive leakages). For radioprotection purposes, a compensation filter package can be developed with the help of the MCNP4b code for the quantity $\mathrm{H}^{*}(10)$ (suitable for local dose measurement). However, sensor heads for the dose quantity $\mathrm{Hp}(10)$ would find a major application for radioprotection and can be worn by a nuclear worker in order to monitor the individual dose equivalent at fixed periods according to the radioprotection rules.

In addition to the nuclear domain, these new sensors could be used for medical treatments or medical imaging involving photons. Radiotherapy needs an external or in vivo monitoring of the doses absorbed by a patient during cancer tumour treatment. The doctor would have at his disposal the deposited dose evolution and can

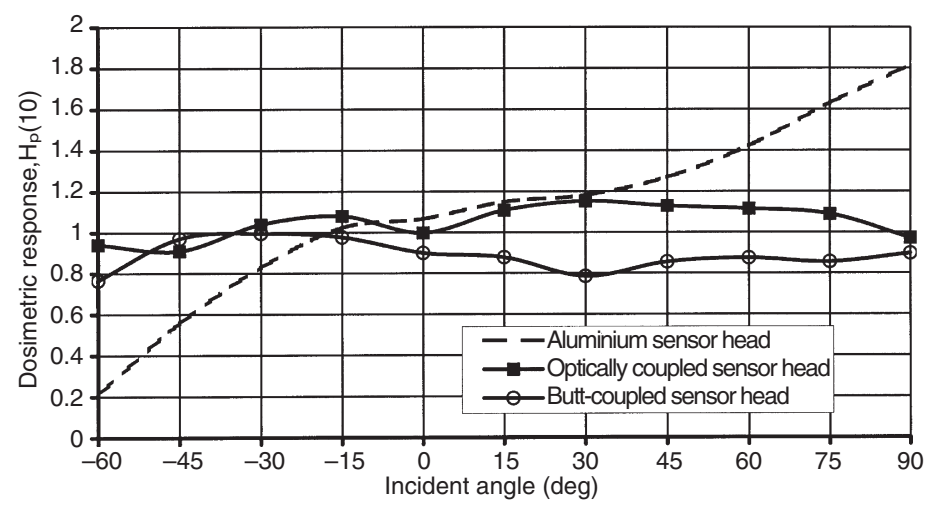

Figure 8. Calculated $\mathrm{H}_{\mathrm{p}}(10)$ response plotted against radiation incidence angle for several fibre remote detectors $\left(90^{\circ}\right.$ is parallel to fibre axis). 


\section{G. RANCHOUX, S. MAGNE, J. P. BOUVET and P. FERDINAND}

optimise the tumour irradiation in real time, with the best protection for surrounding tissues. Finally, the doses absorbed by the hands of surgeons working under $\mathrm{X}$ ray could be monitored with a better accuracy. been done under a joint research grant of CEA and Region Languedoc-Roussillon, France. Gilles Ranchoux thanks Pr. Jean Fesquet and Pr. Jean Gasiot from University of Montpellier, France for fruitful discussions.

\section{ACKNOWLEDGEMENTS}

This work is partially funded by COGEMA and has

\section{REFERENCES}

1. Gasiot, J., Braunlich, P. and Fillard, J. P. Nanosecond Infrared Laser Stimulation of Luminescence in Rare-earth Doped Sulphides. Appl. Phys. Lett. 40(5), 376-378 (1982).

2. Roy, O., Magne, S., Gaucher, J. C., Albert, L., Dusseau, L., Bessière, J. C. and Ferdinand, P. All Optical Fibre Sensor Based on Optically Stimulated Luminescence for Radiation Detection. In: Proc. 12th Optical Fiber Sensor Conference, Williamsburg (VA), USA (1997).

3. Akselrod, M. S., Lucas, A. C., Polf, J. C. and McKeever, S. W. S. Optically Stimulated Luminescence of Alumina. Radiat. Meas. 29(3-4), 391-399 (1998).

4. Landauer Inc, Crystal Growth Division, 723 1/2 Eastgate, Stillwater, OK 74074, USA.

5. Justus, B. L., Pawlovich, K. J., Merritt, C. D. and Huston, A. L. Optically and Thermally Stimulated Luminescence Characteristics of $\mathrm{Cu}^{+}$-doped Fused Quartz. Radiat. Prot. Dosim. 81(1), 5-10 (1999).

6. Justus, B. L. Naval Research Laboratory, Optical Physics Branch, Code 5611, Washington, DC 20375-5338, USA.

7. Templer, R. H. Measurements on some Characteristics of BaFBr:Eu ${ }^{2+}$ Relevant to its Use as a Storage Phosphor for X-ray Diffraction Imaging. Nucl. Instrum. Methods Phys. Res. A300, 357-366 (1991).

8. Spaeth, J. M. Universität-GH Paderborn, FB6 - Experimental physik, 33095 Paderborn, Germany.

9. Trinkler, L. E., Trinkler, M. F. and Popov, A. I. Stimulation Energy of X-ray Storage Material KBr:In. Phys. Status Solidi b 180(1), K31 (1993).

10. Berzina, B. Institute of Solid-State Physics, University of Latvia, Kengaraga Str. 8, Riga (LV) 1063, Latvia.

11. XTM Los Alamos National Laboratory.

12. McKeever, S. W. S., Akselrod, M. S., Colyott, L. E., Agersnap Larsen, N., Polf, J. C. and Whitley, V. Characterisation of $\mathrm{Al}_{2} \mathrm{O}_{3}$ for Use in Thermally and Optically Stimulated Luminescence Dosimetry. Radiat. Prot. Dosim. 84(1-4), 163-168 (1999).

13. Grosswendt, B. Conversion Coefficients for Calibrating Individual Photon Dosemeters in Terms of Dose Equivalent Defined in an ICRU Tissue Cube and PMMA Slabs. Radiat. Prot. Dosim. 32(4), 219-231 (1990). 